Ismail Affandy Siregar \& La Ode Abdul Rahman

Peran Aplikasi M-Health dalam Promosi Kesehatan Aktivitas Fisik

\title{
Peran Aplikasi M-Health Dalam Promosi Kesehatan Aktivitas Fisik
}

\author{
Ismail Affandy Siregar ${ }^{1}$, La Ode Abdul Rahman ${ }^{2}$ \\ ${ }^{1)}$ Program Pascasarjana Fakultas Ilmu Keperawatan Universitas Indonesia \\ ${ }^{2)}$ Fakultas Ilmu Keperawatan Universitas Indonesia
}

Korespondensi penulis: ismailaffandy@gmail.com

\begin{abstract}
Abstrak
Penyakit Tidak Menular (PTM) meliputi asma, PPOK, kanker, gagal jantung, stroke, gagal ginjal kronik. Penyakit tidak menular merupakan masalah kesehatan terbesar di dunia pada abad ke 21. Salah satu faktor penyebabnya adalah kurangnya aktifitas fisik yang dilakukan. Sebagian besar masyarakat beranggapan bahwa aktifitas fisik tidak begitu penting padahal kurangnya aktifitas fisik dapat menyebabkan penyakit tidak menular. Kurangnya aktivitas fisik termasuk pada kategori faktor resiko penyakit tidak menular yang dapat diubah sehingga pendekatan promosi kesehatan dapat dilakukan melalui peningkatan aktivitas fisik. Salah satu upaya promotif dalam meningkatkan aktivitas fisik ialah dengan menggunakan aplikasi mHealth. Penelitian ini menggunakan metode tinjauan pustaka (literatur review) untuk memberikan gambaran tentang mhealth berhubungan dengan aktivitas fisik dan pengaruh mHealth terhadap peningkatan aktivitas fisik. Berdasarkan hasil telaah dan review sebelas jurnal disimpulkan bahwa mHealth dapat mendorong seseorang untuk mau melakukan aktivitas fisik. Fitur dalam mHealth berhubungan dengan aktivitas fisik yang membantu dalam melakukan aktivitas fisik diantaranya petunjuk melakukan jenis aktivitas fisik, pengingat untuk melakukan aktivitas fisik, motivasi untuk melakukan aktivitas fisik, tujuan yang akan dicapai, evaluasi diri terhadap latihan aktivitas fisik, menganalisa fakor dukungan sosial dan lingkungan dalam aktivitas fisik. Perlu dikembangkannya fitur-fitur yang ada pada aplikasi mHealth berdasarkan sumber yang jelas dan pakar-pakar kesehatan yang terkait oleh pemerintah secara gratis.
\end{abstract}

Kata kunci : mHealth; aktifitas fisik; promosi kesehatan

\section{LATAR BELAKANG}

Penyakit Tidak menular (PTM) adalah Penyakit kronik yang tidak menular yang terdiri dari penyakit kardiovaskular, kanker, diabetes penyakit pernapasan seperti asma dan penyakit paru obstruksi kronik (Sommer et al., 2015). PTM merupakan penyebab kematian terbesar di dunia dan pada tahun 2012 angka kematian akibat PTM adalah 38 juta orang atau sekitar (68\%) dari 56 juta kematian di seluruh dunia (WHO, 2014). Di Indonesia angka kejadian (PTM) merupakan masalah kesehatan terbesar dan jenis PTM yang paling tinggi angka kejadiannya ialah hipertensi dan stroke (KEMENKES RI, 2018).

World Health Organization (WHO) telah menetapkan empat faktor resiko yang berkaitan dengan perilaku individu yang dapat menyebabkan PTM yaitu kebiasaan merokok, aktivitas fisik yang rendah, konsumsi alkohol berlebihan, dan diet yang tidak sehat (WHO, 2014). Faktor -faktor resiko yang menyebabkan (PTM) di indonesia sama dengan faktor resiko (PTM) 
Ismail Affandy Siregar \& La Ode Abdul Rahman

Peran Aplikasi M-Health dalam Promosi Kesehatan Aktivitas Fisik

secara global (KEMENKES RI, 2018). Perilaku yang menyebabkan seseorang enggan untuk melakukan aktivitas fisik dan berusaha untuk meminimalkan aktivitas fisiknya akan dapat menyebabkan berbagai macam penyakit (PTM) seperti hipertensi dan stroke dan kondisi tersebut semakin mempercepat berbagai penyakit jika diikuti kebiasaan diet yang tidak sehat dan juga minuman alkohol berlebihan serta merokok (Wu et al., 2015).

Menurut Schoeppe (2016)

Promosi Kesehatan yang berfokus pada perubahan perilaku agar individu mau melakukan aktifitas fisik untuk mencegah (PTM) merupakan langkah strategis. Menurut Aspinall \& Munro (2019) aktivitas fisik yang dapat dilakukan adalah latihan kardiovaskular seperti berlari, atau berjalan 75 menit setiap satu minggu untuk aktifitas fisik berat atau 150 menit untuk aktivitas fisik tingkat menengah namun hal tersebut dapat disesuaikan kepada individu masing masing tegantung dampak yang dirasakan. Aktivitas fisik juga dapat di lakukan dalam aktivitas sehari hari jika tidak memiliki waktu khusus (Aspinall \& Munro, 2019). Kendala saat ini berdasarkan penelitian yang dilakukan masih banyak masyarakat mengganggap bahwa aktivitas fisik tidak berhubungan dengan penyakit (PTM) (Baretta et al., 2019). Sebagian masyarakat mengatakan bahwa mereka tidak memiliki panduan dalam aktivitas fisik serta suatu alat yang dapat mengingatkan, memotivasi masyarakat untuk melakukan aktivitas fisik (Reilly \& Spruijt-metz, 2014).

\section{METODE}

Jurnal yang digunakan dalam studi ini adalah jurnal-jurnal yang membahas mengenai topik dengan kata kunci yaitu: mobile health physical activity /smarthphone apps physical activity/physical activity/Health Information Technology. Penelusuran jurnal akademik melalui Online Database diantaranya: ScienceDirect, Clinical Key, dan ProQuest dari tahun 20152019. 
Ismail Affandy Siregar \& La Ode Abdul Rahman

Peran Aplikasi M-Health dalam Promosi Kesehatan Aktivitas Fisik

Tabel 1. Hasil Penelusuran Literatur

\begin{tabular}{|c|c|c|c|c|c|c|}
\hline No & Penulis/Tahun & Judul Penelitian & Nama Jurnal & Tujuan penelitian & $\begin{array}{c}\text { Metode } \\
\text { Penelitian }\end{array}$ & Hasil Penelitian \\
\hline 1 & Coughlin et al. (2016) & $\begin{array}{l}\text { A Review of } \\
\text { Smartphone } \\
\text { Applications for } \\
\text { Promoting Physical } \\
\text { Activity }\end{array}$ & $\begin{array}{l}\text { Jacobs J } \\
\text { Community Med }\end{array}$ & $\begin{array}{l}\text { Menganalisa } \\
\text { pengaruh mhealth } \\
\text { dalam peningkatan } \\
\text { aktivitas fisik }\end{array}$ & $\begin{array}{l}\text { Literature } \\
\text { review }\end{array}$ & $\begin{array}{l}\text { Aplikasi } m \text { Health memberikan } \\
\text { pengaruh positif terhadap } \\
\text { peningkatan aktivitas fisik. } \\
\text { Pengguna mHealth merasa } \\
\text { terbantu dengan adanya } \\
\text { mHealth karena terdapat fitur } \\
\text { seperti pengingat aktivitas } \\
\text { fisik, tujuan yang akan dicapai, } \\
\text { hasil yang telah dicapai dan } \\
\text { motivasi untuk melakukan } \\
\text { aktivitas fisik }\end{array}$ \\
\hline 2 & Anouk et al. (2015) & $\begin{array}{l}\text { Apps to promote } \\
\text { physical activity } \\
\text { among adults and } \\
\text { content analysis }\end{array}$ & $\begin{array}{l}\text { Internasional } \\
\text { Journal Of } \\
\text { Behavioral } \\
\text { Nutrition and } \\
\text { Physical Activity }\end{array}$ & $\begin{array}{l}\text { Menganalisa } \\
\text { intervensi } 64 \text { aplikasi } \\
\text { mHealth berhubungan } \\
\text { dengan aktivitas fisik } \\
\text { dari iTunes dan } \\
\text { Google Play } \\
\text { berdasarkan } \\
\text { taxonomy teknik } \\
\text { perubahan perilaku }\end{array}$ & $\begin{array}{l}\text { Integrative- } \\
\text { narrative review }\end{array}$ & $\begin{array}{l}\text { Rata-rata aplikasi mHealth } \\
\text { menggunakan lima teknik } \\
\text { perubahan perilaku yaitu self } \\
\text { monitoring, providing } \\
\text { feedback on perfomance, goal } \\
\text { setting, plan sosial support } \\
\text { providing contingent rewards, }\end{array}$ \\
\hline
\end{tabular}


Ismail Affandy Siregar \& La Ode Abdul Rahman

Peran Aplikasi M-Health dalam Promosi Kesehatan Aktivitas Fisik

Schoeppe et al.

(2016)

\begin{tabular}{lll}
\hline \multirow{4}{*}{ Baretta et al. (2019) } & Improving Physical & Advances in \\
& Activity mHealth & human Computer \\
& Interventions: & interaction \\
& Development of a & \\
& Computational & \\
& Model of Self- & \\
& Efficacy Theory to & \\
& Define Adaptive & \\
& Goals for Exercise & \\
& Promotion & \\
\hline
\end{tabular}

Manfaat intervensi Systematic Intervensi melalui aplikasi mHealth pada Review peningkatan aktivitas fisik, perbaikan diit nutrisi, sedentary behaviour

untuk memperbaiki diet nutrisi, peningkatan aktivitas fisik dan sedentary behaviour menunjukkan dampak yang mendukung untuk pengubahan perilaku pada anak-anak dan dewasa. Penggabungan intervensi dalam memperbaiki diet nutrisi, peningkatan aktivitas fisik dan sedentary behaviour lebih efektif dari pada Intervensi tunggal.

$\begin{array}{lll}\begin{array}{l}\text { Pengembangan self } \\ \text { efficacy theory }\end{array} & \begin{array}{l}\text { Literature } \\ \text { Review }\end{array} & \begin{array}{l}\text { Hasil pengembangan } \\ \text { aplikasi ini menyarankan }\end{array} \\ \text { untuk menentukan } & & \text { bahwa setiap aplikasi harus } \\ \text { tujuan dalam } & & \text { menentukan komponen- } \\ \text { peningkatan } & & \text { komponen tujuan yang } \\ \text { aktivitas fisik pada } & \text { harus dicapai dan } \\ \text { aplikasi } \text { mHealth } & \text { disesuaikan dengan } \\ & \text { kemampuan penggunanya. }\end{array}$


Ismail Affandy Siregar \& La Ode Abdul Rahman

Peran Aplikasi M-Health dalam Promosi Kesehatan Aktivitas Fisik

\begin{tabular}{|c|c|c|c|c|c|c|}
\hline 6 & Nielsen et al. (2019) & $\begin{array}{l}\text { Preferences for } \\
\text { mHealth physical } \\
\text { activity interventions } \\
\text { during } \\
\text { chemotherapy for } \\
\text { breast cancer: } a \\
\text { qualitative } \\
\text { evaluation }\end{array}$ & $\begin{array}{l}\text { Supportive care in } \\
\text { cancer }\end{array}$ & $\begin{array}{l}\text { Mengidentifikasi } \\
\text { pengaruh mHealth } \\
\text { physical activity } \\
\text { dalam peningkatan } \\
\text { aktivitas fisik pasien } \\
\text { kanker payudara }\end{array}$ & $\begin{array}{l}\text { Qualitative } \\
\text { research }\end{array}$ & $\begin{array}{l}\text { Hasil peneltian disimpulkan } \\
\text { bahwa penderita kanker } \\
\text { payudara yang sedang } \\
\text { menjalani kemoterapi } \\
\text { membutuhkan aplikasi } \\
\text { mHealth dalam upaya } \\
\text { menjaga kualitas hidup } \\
\text { pasien kanker payudara }\end{array}$ \\
\hline 7 & $\begin{array}{l}\text { O'Reilly et al. } \\
\text { (2014) }\end{array}$ & $\begin{array}{lr}\text { Current } & \text { mHealth } \\
\text { Technologies for } & \text { for } \\
\text { Physical } & \text { Activity } \\
\text { Assessment } & \text { and } \\
\text { Promotion } & \end{array}$ & $\begin{array}{l}\text { American Journal } \\
\text { Preventive } \\
\text { Medicine }\end{array}$ & $\begin{array}{l}\text { Mengidentifikasi } \\
\text { pengaruh } \text { mHealth } \\
\text { terhadap } \\
\text { pengukuran kualitas } \\
\text { aktivitas fisik dan } \\
\text { perubahan perilaku } \\
\text { dalam peningkatan } \\
\text { aktivitas fisik } \\
\end{array}$ & $\begin{array}{l}\text { Systematic } \\
\text { Review }\end{array}$ & $\begin{array}{l}\text { Hasil penelitian disimpulkan } \\
\text { bahwa aplikasi mHealth } \\
\text { berpengaruh terhadap } \\
\text { peningkatan aktivitas fisik. } \\
\text { mHealth membantu dalam } \\
\text { analisis pengkajian dan } \\
\text { intervensi dalam aktivitas } \\
\text { fisik }\end{array}$ \\
\hline 8 & $\begin{array}{l}\text { Vandelanotte et al. } \\
\text { (2015) }\end{array}$ & $\begin{array}{l}\text { Past, Present and } \\
\text { Future of eHealth } \\
\text { and mHealth } \\
\text { Research to Improve } \\
\text { physical Activity and } \\
\text { Dietary Behaviors }\end{array}$ & $\begin{array}{l}\text { Journal of } \\
\text { Nutrition } \\
\text { Education and } \\
\text { Behavior }\end{array}$ & $\begin{array}{l}\text { Memberikan } \\
\text { penjelasan tentang } \\
\text { peran mHealth } \\
\text { dalam tiga masa } \\
\text { waktu }\end{array}$ & $\begin{array}{l}\text { Literature } \\
\text { Review }\end{array}$ & $\begin{array}{lr}\text { Hasil } & \text { penelitian } \\
\text { menyimpulkan bahwa } & \text { mealth memiliki peranan } \\
\text { mHealth } & \text { utama dalam peningkatan } \\
\text { aktivitas fisik pada masa } \\
\text { yang akan datang } \\
\text { disebabkan tingginya } \\
\text { tingkat kesibukan manusia. } \\
\text { Perlunya dikembangkan } \\
\text { aplikasi mHealth yang } \\
\text { komprehensi karena } \\
\text { mHealth akan menjadi peran } \\
\text { utama dalam peningkatan } \\
\text { aktivitas fisik } \\
\text { Hasil }\end{array}$ \\
\hline
\end{tabular}

Jurnal Kesehatan, vol. 9, 2020, pISSN: 2301-783X, eISSN: 2721-8007 


\begin{tabular}{|c|c|c|c|c|c|c|}
\hline & & & & & & $\begin{array}{l}\text { menyimpulkan bahwa } \\
\text { mHealth berpengaruh } \\
\text { terhadap motivasi individu } \\
\text { untuk melakukan aktivitas } \\
\text { fisik. }\end{array}$ \\
\hline 9 & $\begin{array}{l}\text { Eckerstorfer et al. } \\
\text { (2018) }\end{array}$ & $\begin{array}{l}\text { Key Elements of } \\
\text { mHealth } \\
\text { Interventions to } \\
\text { Successfully } \\
\text { Increase Physical } \\
\text { Activity: Meta- } \\
\text { Regression }\end{array}$ & $\begin{array}{l}\text { JMIR Mhealth } \\
\text { and Uhealth }\end{array}$ & $\begin{array}{l}\text { Menganalisa } \\
\text { element yang } \\
\text { berkontribusi dalam } \\
\text { intervensi aktivitas } \\
\text { fisik melalui } \\
\text { mHealth }\end{array}$ & $\begin{array}{l}\text { Systematic } \\
\text { Review }\end{array}$ & 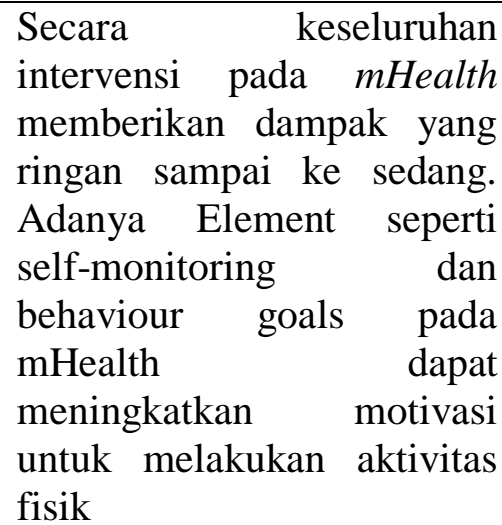 \\
\hline 10 & Direito et al. (2015) & $\begin{array}{l}\text { Smartphone apps to } \\
\text { improve fitness and } \\
\text { increase physical } \\
\text { activity among } \\
\text { young people: } \\
\text { protocol of the Apps } \\
\text { for IMproving } \\
\text { FITness (AIMFIT) } \\
\text { randomized } \\
\text { controlled trial }\end{array}$ & $\begin{array}{l}\text { BioMed Central } \\
\text { Public Health }\end{array}$ & $\begin{array}{l}\text { Melakukan } \\
\text { pengujian aplikasi } \\
\text { mHealth kepada } \\
\text { target peneliti yang } \\
\text { telah ditentukan } \\
\text { dengan mengamati } \\
\text { behaviours skill } \\
\text { change } \\
\text { development, } \\
\text { physical activity } \\
\text { behaviour change, } \\
\text { dan fitness change } \\
\text { target peneliti } \\
\end{array}$ & $\begin{array}{l}\text { Random } \\
\text { Control Trial }\end{array}$ & $\begin{array}{l}\text { Hasil penelitian } \\
\text { menyimpulkan bahwa } \\
\text { kualitas mHealth physical } \\
\text { activity mempengaruhi } \\
\text { kemauan seseorang untuk } \\
\text { melakukan aktivitas fisik. } \\
\text { Kualitas aplikasi mHealth } \\
\text { yang baik dapat dibuat } \\
\text { dengan mengacu pada aspek } \\
\text { enjoyment, competence, } \\
\text { autonomy, relatedness dan } \\
\text { self eficacy dari suatu } \\
\text { mHealth physical activity. }\end{array}$ \\
\hline
\end{tabular}


Ismail Affandy Siregar \& La Ode Abdul Rahman

Peran Aplikasi M-Health dalam Promosi Kesehatan Aktivitas Fisik

11 Mollee et al (2017)
What technological

features are used in smartphone apps

that promote

physical activity? A

review and content

analysis
Springer

Menganalisis fitur yang paling banyak digunakan dalam mHealth aktivitas fisik
Systematic review

Hasil penelitian terkait fitur aplikasi yang paling banyak pada mHealth terkait aktivitas fisik adalah data pencapaian aktivitas fisik, pemberian penghargaan dan diskusi dengan sesama pengguna mengenai jenis aktivitas fisik terbaru, petunjuk dan motivasi terkait aktivitas fisik, integrasi dengan sumber eksternal pendukung aktivitas fisik, bentukbentuk hukuman ketika gagal dalam pencapaian target aktivitas fisik, fasilitas untuk berdiskusi dengan pakar kesehatan terkait aktivitas fisik. 
Ismail Affandy Siregar \& La Ode Abdul Rahman

Peran Aplikasi M-Health dalam Promosi Kesehatan Aktivitas Fisik

\section{PEMBAHASAN}

Menurut data WHO (2014) salah satu upaya yang dapat dilakukan dalam pencegahan (PTM) adalah dengan mengubah perilaku individu agar meningkatkan frekuensi aktivitas fisiknya sehingga terhindar dari (PTM). Hasil penelitian yang dilakukan Kvintová \& Sigmund, (2016) aktivitas fisik yang dilakukan secara rutin akan membuat tubuh menjadi sehat dan terhindar dari penyakit (PTM) selain itu tubuh yang sehat akan menjadikan mental dan jiwa menjadi sehat. Aplikasi mHealth adalah strategi promosi kesehatan di bidang teknologi. Saat ini penggunaan teknologi dalam peradaban manusia sudah sangat besar khususnya di bidang telekomunikasi menggunakan mobile phone/smartphone (Coughlin et al., 2016). Hasil penelitian membuktikan pengguna smartphone di indonesia mencapai 70,96\% (APJII, 2018). Banyaknya pengguna smartphone di indonesia tentunya merupakan kesempatan yang bisa digunakan untuk melakukan promosi kesehatan khususnya berkaitan dengan aktivitas fisik melalui mobile phone/smartphone. Penggunaan smartphone pada abad ke-21 tidak hanya berfokus pada komunikasi tetapi semakin meluas dalam memenuhi berbagai gaya hidup sehingga memungkinkan adanya aplikasi-aplikasi lain dalam smartphone yang membantu kebutuhan sehari-hari termasuk pada bidang kesehatan (Romeo et al., 2019).

Aplikasi mHealth adalah aplikasi kesehatan yang sangat berguna sebagai sarana untuk meningkatkan aktivitas fisik karena penggunaannya mudah, dapat diakses kapan saja, biaya penggunaannya murah, dapat dijangkau masyarakat luas dan jenis aktivitas fisik yang dapat dilakukan lengkap dan dapat terintegrasi dengan aktivitas sehari hari (Nielsen et al., 2019). Aplikasi mHealth bertujuan untuk mengubah perilaku agar mau melakukan aktivitas fisik untuk mencegah (PTM) sehingga dalam pembuatan aplikasi mHealth harus berlandaskan pada teori perubahan perilaku kesehatan (Coughlin et al, 2016). Penggunaan aplikasi mHealth ini memanfaatkan teknologi informasi dan komunikasi khususnya internet dalam upaya peningkatan pelayanan di bidang kesehatan (Vandelanotte et al., 2016). Dalam penggunaannya aplikasi mHealth juga memanfaatkan teknologi yang ada dalam smartphone seperti GPS (Global Position System), Accelerometry, sensor biological yang akan membantu dalam mengumpulkan data kesehatan pengguna dan membantu pengguna untuk memantau hasil capaian aktivitas fisiknya (Lee et al., 2019).

Aplikasi mHealth terkait aktivitas fisik telah tersedia di beberapa jenis perusahaan komunikasi seperti (iPhone, Android, Nokia dan Blackberry). Model promosi kesehatan yang ditawarkan oleh mHealth tersebut diantaranya petunjuk melakukan berbagai jenis aktivitas fisik, pengingat untuk melakukan aktivitas fisik, motivasi-motivasi untuk berkaitan dengan aktivitas fisik, tujuan yang akan dicapai, evaluasi diri terhadap latihan aktivitas fisik, menganalisa fakor pendukung dalam aktivitas fisik dari kehidupan sosial dan lingkungan (Coughlin et al., 2016). Penelitian yang dilakukan oleh Middelweerd et al. (2014) menentukan aplikasi mHealth yang dapat digunakan untuk membantu kita dalam meningkatkan aktivitas fisik. 
Ismail Affandy Siregar \& La Ode Abdul Rahman

Peran Aplikasi M-Health dalam Promosi Kesehatan Aktivitas Fisik

Tabel 2. Aplikasi mHealth Yang Dapat Digunakan Untuk Membantu Dalam Meningkatkan Aktivitas Fisik

\begin{tabular}{|c|c|c|c|c|c|}
\hline No & Nama & Penyedia & No & Nama & Penyedia \\
\hline 1 & $\begin{array}{l}\text { RunKeeper-GPS Track } \\
\text { Run Walk }\end{array}$ & Google play & 1 & $\begin{array}{l}\text { Big Welsh Walking } \\
\text { Challenge }\end{array}$ & iTunes \\
\hline 2 & Sworkit Pro & Google play & 2 & GymPush & iTunes \\
\hline 3 & $\begin{array}{l}\text { Be Fit, Stay Fit } \\
\text { Challenge }\end{array}$ & Google play & 3 & Hubbub Health & iTunes \\
\hline 4 & $\begin{array}{l}\text { Endomondo Sports } \\
\text { Tracker }\end{array}$ & Google play & 4 & $\begin{array}{l}\text { My Pocket Coach (a life, } \\
\text { wellness \& success } \\
\text { coach) }\end{array}$ & iTunes \\
\hline 5 & $\begin{array}{l}\text { Everywhere Run! - GPS } \\
\text { Run Walk }\end{array}$ & Google play & 5 & $\begin{array}{l}\text { Sixpack - Personal } \\
\text { Trainer }\end{array}$ & iTunes \\
\hline
\end{tabular}

Aplikasi diatas dipilih berdasarkan penilaian yang paling mendekati terhadap teori perubahan perilaku dalam kesehatan. Aplikasi mHealth dapat diunduh dari google playstore untuk smartphone berbasis android dan juga iTunes untuk pengguna Apple. Aplikasi yang ditawarkan oleh penyedia applikasi ada dua jenis yaitu berbayar dan tidak berbayar. Berdasarkan penelitian yang dilakukan oleh Middelweerd et al., (2014). Hasil telaah jurnal yang telah dilakukan didapatkan bahwa aplikasi mHealth berhubungan dengan aktivitas fisik memiliki pengaruh positif terhadap kemauan seseorang untuk melakukan aktivitas fisik namun ada beberapa hal yang perlu menjadi perhatian bahwa tidak semua mHealth berkaitan dengan aktivitas fisik yang tersedia di googleplay dan iTunes dapat digunakan, berdasarkan hasil penelitian Anouk et al, (2015) terdapat aplikasi yang tidak memiliki tinjauan literatur yang jelas terkait intervensi/fitur disediakan sehingga penting untuk melakukan konsultasi terkait pemilihan aplikasi $m$ Health dengan tenaga kesehatan agar diperoleh aplikasi yang tepat.

Pertimbangan utama dalam pemilihan Aplikasi mHealth yang dapat digunakan dari googleplay atau itunes yang pertama bahwa setiap intervensi yang disediakan haruslah memiliki landasan teori yang jelas, kedua ialah adanya fitur- fitur seperti data pencapaian aktivitas fisik, pemberian penghargaan dan diskusi dengan sesama pengguna mengenai jenis aktivitas fisik terbaru, petunjuk dan motivasi terkait aktivitas fisik, integrasi dengan sumber eksternal pendukung aktivitas fisik, bentuk-bentuk hukuman ketika gagal dalam pencapaian target aktivitas fisik, fasilitas untuk berdiskusi dengan pakar kesehatan terkait aktivitas fisik Mollee et al (2017). Penelitian yang dilakukan oleh Direito (2015) menyimpulkan semakin baik kualitas mHealth maka motivasi seseorang untuk melakukan aktivitas fisik semakin besar. Fungsi mHealth saat ini dan dimasa yang akan datang menurut Vandelanotte et al, (2015) memegang peranan penting dalam peningkatan aktivitas fisik disebabkan karena kemajuan teknologi yang begitu pesat dan tingkat produktivitas individu semakin tinggi yang menyebabkan seseorang tidak memiliki waktu untuk pergi ke pusat kebugaran untuk berolahraga sehingga diperlukan suatu aplikasi yang dapat mengintegrasikan aktivitas sehari- hari dengan tetap melakukan aktivitas fisik untuk kebugaran tubuh.

Peran mHealth ini tentunya harus diimbangi dengan kualitas mHealth yang dihadirkan sehingga diharapkan dari pemerintah khususnya pada instansi kesehatan agar membuat aplikasi mHealth 
Ismail Affandy Siregar \& La Ode Abdul Rahman

Peran Aplikasi M-Health dalam Promosi Kesehatan Aktivitas Fisik

sesuai dengan literatur yang jelas, kualitas yang baik dan diberikan secara gratis kepada masyarakat karena saat ini aplikasi

\section{KESIMPULAN}

Peningkatan aktivitas fisik yang baik akan mencegah dari berbagai masalah kesehatan terutama PTM. Salah satu tujuan utama kehadiran mHealth dalam upaya peningkatan kesehatan fisik adalah untuk mengintegrasikan aktivitas fisik dalam kegiatan sehari hari agar aktivitas fisik tetap dapat dilakukan bersamaan dengan aktivitas sehari-hari sehingga aktivitas fisik dapat dilakukan secara rutin. Aktivitas fisik yang rutin dilakukan akan membentuk fisik yang kuat dan jiwa yang sehat dan terhindar dari berbagai penyakilt terutama (PTM) sehingga jumlah penderita (PTM) di indoensia dapat menurun. Langkah selanjutnya yang perlu dilakukan adalah perlunya dikembangkan suatu aplikasi mHealth terkait aktivitas fisik yang mutakhir dan terintegrasikan dengan program pemerintah dibidang pelayanan kesehatan mengingat penyakit (PTM) merupakan masalah kesehatan terbesar di indonesia sehingga diperlukan usaha yang maksimal untuk menekan jumlah penderita (PTM).

\section{DAFTAR PUSTAKA}

APJII.

(2018).

BULETINAPJIIEDISI23April201

8.pdf (p. 1). p. 1. Retrieved from https://apjii.or.id/downfile/file/BU LETINAPJIIEDISI23April2018.p df

Aspinall, S., \& Munro, A. (2019). Knowledge and global health: Reducing the burden of noncommunicable diseases using physical activity. British Journal of Sports Medicine, 53(14), 845846.

https://doi.org/10.1136/bjsports2019-101105

Baretta, D., Sartori, F., Greco, A., D’Addario, M., Melen, R., \&
mHealth berkaitan dengan aktivitas fisik belum ada dibuat oleh Pemerintah yang mengurusi bidang kesehatan.

Peran mHealth dalam promosi kesehatan aktvitas fisik sangat penting bagi perawat karena akses informasi kesehatan dapat dilakukan kapan saja dan dimana saja sehingga informasi kesehatan dalam promosi kesehatan untuk meningkatkan aktivitas fisik dapat diterima secara cepat. Kecepatan penerimaan informasi memiliki dampak yang baik pada promosi kesehatan karena semakin cepat informasi diterima semakin cepat intervensi yang dapat dilakukan. Aplikasi mHealth akan membantu perawat dalam upaya promosi kesehatan. Individu dengan segala kegiatannya tidak bisa selalu bersama dengan perawat komunitas, kehadiran aplikasi mHealth akan membantu individu untuk mendapatkan informasi kesehatan berkaitan dengan aktifitas fisik sehingga aktifitas fisik dapat tetap terlaksana secara rutin. Perawat komunitas juga harus mengevaluasi klien dalam penggunaan aplikasi mHealth agar tindakan yang dilakukan tepat dan baik.

Steca, P. (2019). Improving Physical Activity mHealth Interventions: Development of a Computational Model of SelfEfficacy Theory to Define Adaptive Goals for Exercise Promotion. Advances in HumanComputer Interaction, 2019. https://doi.org/10.1155/2019/3068 748

Coughlin, S. S., Whitehead, M., Sheats, J. Q., Mastromonico, J., \& Smith, S. (2016). A Review of Smartphone Applications for Promoting Physical Activity. Jacobs Journal of Community Medicine, 2(1), 114. Retrieved from 
Ismail Affandy Siregar \& La Ode Abdul Rahman

Peran Aplikasi M-Health dalam Promosi Kesehatan Aktivitas Fisik

http://www.ncbi.nlm.nih.gov/pub med/27034992\%0Ahttp://www.p ubmedcentral.nih.gov/articlerende r.fcgi?artid=PMC4811195

KEMENKES RI. (2018). RISKESDAS 2018: Executive Summary.

Kvintová, J., \& Sigmund, M. (2016). Physical activity, body composition and health assessment in current female university students with active and inactive lifestyles. Journal of Physical Education and Sport, 16(1), 627-632. https://doi.org/10.7752/jpes.2016. s1100

Lee, A. M., Chavez, S., Bian, J., Thompson, L. A., Gurka, M. J., Williamson, V. G., \& Modave, F. (2019). Efficacy and effectiveness of mobile health technologies for facilitating physical activity in adolescents: Scoping review. Journal of Medical Internet Research, 21(2), 1-14. https://doi.org/10.2196/11847

Middelweerd, A., Mollee, J. S., van der Wal, C. N., Brug, J., \& te Velde, S. J. (2014). Apps to promote physical activity among adults: A review and content analysis. International Journal of Behavioral Nutrition and Physical Activity, 11(1), 1-9. https://doi.org/10.1186/s12966014-0097-9

Nielsen, A. M., Welch, W. A., Gavin, K. L., Cottrell, A. M., Solk, P., Torre, E. A., ... Phillips, S. M. (2019). Preferences for mHealth physical activity interventions during chemotherapy for breast cancer: a qualitative evaluation. Supportive Care in Cancer. https://doi.org/10.1007/s00520019-05002-w

Reilly, G. A. O., \& Spruijt-metz, D. (2014). Current mHealth Technologies for Physical Activity
Assessment and Promotion. 45(4), 501-507.

https://doi.org/10.1016/j.amepre.2 013.05.012.Current

Romeo, A., Edney, S., Plotnikoff, R., Curtis, R., Ryan, J., Sanders, I., ... Maher, C. (2019). Can smartphone apps increase physical activity? systematic review and meta-analysis. Journal of Medical Internet Research, 21(3), $1-14$. https://doi.org/10.2196/12053

Schoeppe, S., Alley, S., Van Lippevelde, W., Bray, N. A., Williams, S. L., Duncan, M. J., \& Vandelanotte, C. (2016). Efficacy of interventions that use apps to improve diet, physical activity and sedentary behaviour: A systematic review. International Journal of Behavioral Nutrition and Physical Activity, 13(1). https://doi.org/10.1186/s12966016-0454-y

Sommer, I., Griebler, U., Mahlknecht, P., Thaler, K., Bouskill, K., Gartlehner, G., \& Mendis, S. (2015). Socioeconomic inequalities in non-communicable diseases and their risk factors: An overview of systematic reviews. BMC Public Health, 15(1), 1-13. https://doi.org/10.1186/s12889015-2227-y

Vandelanotte, C., Müller, A. M., Short, C. E., Hingle, M., Nathan, N., Williams, S. L., ... Maher, C. A. (2016). Past, Present, and Future of eHealth and mHealth Research to Improve Physical Activity and Dietary Behaviors. Journal of Nutrition Education and Behavior, Vol. 48, pp. 219228.e1.

https://doi.org/10.1016/j.jneb.201 5.12 .006

WHO. (2014). World Health Organization. (2014). Global 
Ismail Affandy Siregar \& La Ode Abdul Rahman

Peran Aplikasi M-Health dalam Promosi Kesehatan Aktivitas Fisik

status report on noncommunicable diseases 2014. World Health Organization. http://www.who.int/iris/handle/10 665/148114.

Wu, F., Guo, Y., Chatterji, S., Zheng, Y., Naidoo, N., Jiang, Y., ... Kowal, P. (2015). Common risk factors for chronic non-communicable diseases among older adults in china, ghana, mexico, india, russia and south africa: The study on global AGEing and adult health (SAGE) wave 1. BMC Public Health, 15(1), 1-13. https://doi.org/10.1186/s12889-

015-1407-0 